\title{
P01-248
}

\section{AGGESSIVENESS IN PERSONS SUFFERING FROM MAJOR DEPRESSIVE DISORDER}

\section{B. Dutczak}

Psychiatry Department, Medical Academy, Gdansk, Poland

Different types of aggressiveness occur in the course of many mental disorders - including major depressive disorder. In the literature, however, there is no model nor scientific researches that would explain explain the nature, dyrection, and dynamics of involved in this effect.The purpose of this research was to describe intensity and structure of aggressiveness in persons suffering from major depressive disorder. 